All hepatitis B carriers who were $\mathrm{HBeAg}$-positive had high titres of HBsAg; this could not be used as a reliable indicator of the presence of $\mathrm{HBeAg}$, however, because some of the carriers with anti-HBe also had high $\mathrm{HBsAg}$ titres. Generally it has been found that many $\mathrm{HBsAg}$ carriers have neither $\mathrm{HBeAg}$ nor anti-HBe, which reflects the relative insensitivity of immunodiffusion-for example, in our study $29 \%$ of the carriers were e-negative by this test. This number of unclassifiable carriers has made it difficult to evaluate the relation between $\mathrm{HBeAg}$ and raised liver enzyme concentrations reported by Maynard $e t a l^{16}$ and Polesky and Hanson. ${ }^{17}$ By using the more sensitive e-RIA in addition to immunodiffusion we could confirm their observations and show a more precise relation between the presence of $\mathrm{HBeAg}$ and raised enzyme concentrations.

In acute hepatitis B infections serum liver enzyme concentrations are generally much higher than those in carriers and HBeAg is only transiently present. In chronic asymptomatic carriers persistently, though modestly, raised liver enzyme concentrations appear to be a useful indicator of the presence of $e$ antigen and thus of probable infectivity. Indeed, it is interesting to compare the accuracy of using either immunodiffusion or raised enzyme concentrations to identify the $\mathrm{HBeAg}$ positive carriers. Immunodiffusion identified 12 of the 14 HBeAg-positive sera, whereas 13 were identified by finding raised enzyme concentrations, though at the cost of three anti-HBe sera being incorrectly classified.

Testing for the presence of $\mathrm{HBeAg}$ is practicable only for specialised laboratories; on the other hand, estimating liver enzyme concentrations is a routine determination in any general hospital. We consider that when assessing the potential infectivity of an indigenous $\mathrm{HBsAg}$ carrier in the UK estimating liver enzyme concentrations is a simple and accurate alternative to the specific tests for $\mathrm{HBeAg}$.

We wish to thank Dr D S Dane and Dr C H Cameron for their help. RST was supported financially by the Wellcome Trust.

\section{References}

${ }^{1}$ Magnius, L O, and Espmark, J A, fournal of Immunology, 1972, 109, 1017. 2 Okada, K, et al, New England fournal of Medicine, 1976, 294, 746.

${ }^{3}$ Magnius, L O, et al, fournal of the American Medical Association, 1975, 231, 356.

${ }^{4}$ Iwarson, S, Vox Sanguinis, 1978, 34, 311.

${ }^{5}$ Reesink, H W, Vox Sanguinis, 1978, 34, 315.

6 Trepo, C G, et al, Gastroenterology, 1976, 71, 804.

${ }^{7}$ Heathcote, J, Gateau, P, and Sherlock, S, Lancet, 1974, 2, 370.

${ }^{8}$ Heathcote, J, Cameron, C H, and Dane, D S, Lancet, 1974, 1, 71.

9 Tedder, R S, fournal of Medical Virology, 1978. In press.

${ }_{10}$ Mushahwar, I K, et al, fournal of Medical Virology, 1978, 2, 77.

11 Skinhøj, P, American fournal of Epidemiology, 1977, 105, 99.

${ }^{12}$ Nath, N, et al, 30th Annual Meeting of the American Association of Blood Banks, 1977, abstract S 82.

${ }^{13}$ Mazzur, S, and Jones, N, Fournal of Infectious Diseases, 1976, 133, 331.

${ }^{14}$ Blumberg, B S, et al, Archives of Internal Medicine, 1972, 130, 227.

${ }^{15}$ Derso, A, et al, British Medical fournal, 1978, 1, 949.

${ }^{16}$ Maynard, J E, et al, Fournal of Infectious Diseases, 1976, 133, 339.

${ }_{17}$ Polesky, H F, and Hanson, M, 30th Annual Meeting of the American Association of Blood Banks, 1977, abstract S 41.

\title{
Haemodynamic effects of buprenorphine after heart surgery
}

\author{
F L ROSENFELDT, B HOUSTON, D THOMPSON, N NAQUI, A D MALCOLM, \\ B T WILLIAMS, D J COLTART
}

Buprenorphine appears to be safer than morphine for use in patients with reduced cardiac reserve and is of similar analgesic efficacy.

\section{Summary and conclusions}

The effect of buprenorphine on the cardiovascular system was examined in 11 patients during the period of reduced cardiac reserve after open-heart surgery. Within 10 minutes of giving the full analgesic dose $(5, \mu \mathrm{g} / \mathrm{kg}$ ) intravenously the mean heart rate had fallen significantly by six beats $/ \mathrm{min}$. Although in two patients the mean arterial pressure fell by $24 \mathrm{~mm} \mathrm{Hg}$, there was no overall change in mean arterial pressure, carciiac output, or peripheral resistance. In a further six patients buprenorphine was used successfully as the sole analgesic after open-heart surgery.

\footnotetext{
Departments of Cardiology and Cardiovascular Surgery, The Rayne Institute, St Thomas's Hospital, London SE1 7EH

F L ROSENFELDT, MD, FRCS, Kleinwort research fellow (present address: Baker Medical Research Institute, Victoria, Australia)

$B$ HOUSTON, MB, MRCP, research assistant

D THOMPSON, MB, MRCP, cardiac registrar

N NAQUI, MB, MRCP, Kleinwort research fellow

A D MALCOLM, MSC, FRCP(C), Kleinwort research fellow (now consultant physician, Airedale General Hospital, Yorkshire)

B T WILLIAMS, FRCS, consultant cardiac surgeon

D J COLTART, MD, MRCP, consultant physician
}

\section{Introduction}

Buprenorphine, a synthetic derivative of the opium alkaloid thebaine, is a strong new analgesic currently undergoing clinical trial. Initial experience suggests that it has little tendency to produce addiction. ${ }^{1} \mathrm{~A}$ dose of $0.6 \mathrm{mg}$ gives the same degree of pain relief as $15 \mathrm{mg}$ morphine and lasts up to eight hours. ${ }^{2}$ Morphine is a vasodilator and may cause hypotension in the presence of reduced cardiac reserve or hypovolaemia. ${ }^{3}$ This effect is well known after cardiac surgery. Initial studies suggested that buprenorphine exerts less effect on the cardiovascular system than morphine. These studies, however, were carried out on animals, ${ }^{4}$ volunteers, ${ }^{5}$ and postoperative patients ${ }^{6}$ whose cardiovascular systems were normal. We decided to examine the cardiovascular effects of buprenorphine in the period of reduced cardiac reserve after open-heart surgery. The study protocol was approved by the hospital's ethics committee, and all patients gave written informed consent before operation.

\section{Patients and methods}

Eleven patients were studied within 24 hours after open-heart surgery; their average age was 54 years (range 32-67 years) and average weight $66 \mathrm{~kg}$. Operations comprised valve replacement, correction of 
congenital heart surgery, and coronary artery surgery. Two patients were in atrial fibrillation and one received an infusion of adrenaline and isoprenaline throughout. All were mechanically ventilated.

Arterial pressure and left and right atrial pressures were measured via pressure transducers and indwelling catheters. Phasic aortic flow was measured with the Barefoot-Williams extractable aortic electromagnetic flow probe. ${ }^{7}$ Pressure and flow signals and the electrocardiogram were recorded on magnetic tape. The tapes were analysed on a Varian digital computer.

After a 20-minute control period, in which all haemodynamic measurements had to be constant, buprenorphine was given intravenously over 30 seconds at a dose of $5 \mathrm{~kg} / \mathrm{kg}$ body weight. Haemodynamic measurements were recorded for 15 minutes in all patients and for 60 minutes in eight.

In a control group of 11 patients of similar age and weight who were not given any analgesic agent heart rate was recorded over 60 minutes corresponding to the study period. Six other patients received intravenous buprenorphine as their sole analgesic in the first 48 hours after open-heart surgery. In accordance with standard practice in the recovery ward for patients on ventilators the adequacy of pain relief and need for additional medication was assessed by the nursing staff. Statistical analysis was carried with the two-way analysis of variance.

\section{Results}

In the first 15 minutes after buprenorphine the overall mean left atrial pressure, systemic vascular resistance, cardiac output, and arterial pressure did not change significantly from control values; in two patients, however, the mean arterial pressure fell by $24 \mathrm{~mm} \mathrm{Hg}$. Myocardial contractility as assessed by stroke work and left ventricular power also showed no consistent change from control values. The only haemodynamic variable to show a significant change for the group was heart rate, which fell from a control value of 104 beats/min to $99 / \mathrm{min}$ at 10 and 15 minutes $(P<0.001)$.

Results obtained over one hour were similar to those obtained in the first 15 minutes. Only heart rate showed a consistent change, falling to 100 beats $\mathrm{min}$ at 30 minutes and to $99 / \mathrm{min}$ at 60 minutes $(P<0.001)$. In the control group the mean heart rate fell from 102 beats/min at the beginning of the 60 -minute observation period to $100 / \mathrm{min}$ at the end. This change was not significant.

The six patients given buprenorphine as the sole analgesic in the first 48 hours after operation required an average of seven doses of $0.4 \mathrm{mg}$ intravenously. In comparison a group of 10 patients of similar age and weight observed over the same postoperative period needed an average of nine doses of $7 \mathrm{mg}$ papaveretum.

\section{Discussion}

We gave our patients the full analgesic dose of intravenous buprenorphine soon after open-heart surgery. Larger doses have been tried in this unit but confer little additional relief and again have little effect on circulation. Although the immediate period after cardiac surgery is generally a time of circulatory instability, on no occasion did we observe an undesirable effect on the cardiovascular system. The overall mean arterial pressure did not change significantly, the greatest individual fall being $24 \mathrm{~mm} \mathrm{Hg}$. Heart rate was the only variable that showed a consistent change: 10 minutes after giving buprenorphine a bradycardia of six beats/min was observed, which persisted for 60 minutes or more. This may have been due to a direct action of the drug or to an indirect action in relieving tachycardia due to pain and anxiety.

Morphine may lower blood pressure by causing peripheral vasodilatation. This effect may be exaggerated after acute myocardial infarction ${ }^{3}$ or open-heart surgery ${ }^{8}$ when there is limited cardiac reserve or hypovolaemia. Hence after open-heart surgery morphine or papaveretum must be given cautiously in small doses repeated often if necessary to obtain pain relief. Other conventional analgesics are well known to cause haemodynamic changes. ${ }^{9}$

We found that the full analgesic dose of buprenorphine could be given safely as a single intravenous injection. We used it as the sole analgesic in six patients after open-heart surgery. Although we could not measure pain relief, subjective assessment indicated that analgesia was adequate, and in no case was it necessary to resort to an opiate.

We found no adverse effect of buprenorphine on the cardiovascular system. Buprenorphine appears to be a safe analgesic for use in patients with an unstable circulation.

This work was supported by the Kleinwort Trust and a grant from Reckitt and Colman Ltd. We thank $\mathrm{Mr} \mathrm{M}$ Stoate for computer programming, and Dr K MacRae and Professor $\mathrm{P}$ Korner for statistical help.

Requests for reprints should be addressed to: Dr D J Coltart, The Rayne Institute, St Thomas's Hospital, Lambeth Palace Road, London SE1 7EH.

\section{References}

${ }^{1}$ Jasinski, D R, Pevnick, J S, and Griffith, J D, Federation Proceedings, 1977, 36, 1025 .

${ }^{2}$ Downing, J W, Leary, W P, and White, E S, British fournal of Anaesthesia, $1977,49,251$.

3 Thomas, M, et al, British Heart fournal, 1965, 27, 863.

4 Cowan, A, Doxey, J C, and Harry, E J R, British fournal of Pharmacology, $1977,60,547$.

${ }^{5}$ Orwin, J M, in Pain-New Perspectives in Measurement and Management, ed A W Harcus, R B Smith, and B A Whittle, p 141. Edinburgh, Churchill Livingstone, 1977.

${ }^{6}$ Hovell, B C, British Fournal of Anaesthesia, 1977, 49, 913.

${ }^{7}$ Williams, B T, et al, fournal of Thoracic and Cardiovascular Surgery, 1972, 63, 917 .

${ }^{8}$ Morrison, J D, et al, Fournal of Thoracic and Cardiovascular Surgery, 1972, 63, 890 .

${ }^{9}$ Malcolm, A D, and Coltart, D J, in Pain-New Perspectives in Measurement and Management, ed A W Harcus, R B Smith, and B A Whittle, p 41. Edinburgh, Churchill Livingstone, 1977.

(Accepted 13 October 1978)
ONE HUNDRED YEARS AGO We read in the Lyon Medical an interesting article on the difference existing in the climates of different parts of Italy, which contains many valuable hints for practitioners. The climate in the north of the peninsula does not differ much either in dampness or temperature from that of the north of France and England; in the south, the heat and dryness remind one of Africa. The cold is very severe during the bad season in Alexandria, Turin, Pavia, Milan, Guastalla, Modena, and the whole length of the valley of the river Po. In Turin, the mercury sometimes sinks to $30 \cdot 6$ Fahr below the freezing-point. In Aosta, Biella, and Udine, which are situated more to the north and under a higher longitude, the temperature never sinks so low. The winters of Genoa are exceedingly mild, notwithstanding its vicinity to Alexandria and Turin, the glass seldom falling to $26 \cdot 8 \mathrm{Fahr}$. In Naples, Cagliari (Sardinia), and Palermo, the inhabitants complain bitterly of the severe frost when the temperature is only five or six degrees below freezing; and yet the mean temperature of the winter does not differ much in all these places from the temperature of Genoa. It is at Palermo 53 Fahr: at Cagliari 50.36 Fahr; at Naples $48.4 \mathrm{Fahr}$ deg; and very near $48.2 \mathrm{Fahr}$ at Genoa. There is also a very slight difference between the mean winter temperatlires at Leghorn and Rome. The places which are nearer the Mediterranean have a much higher temperature during winter than those which are situated towards the centre of the peninsula. The borders of the Adriatic are much colder than those of the Mediterranean. Thus, at Venice, the mean temperature during winter is only $39 \cdot 27$ Fahr. During the summer, the same places which we have quoted before as being coldest in winter are most exposed to heat. The mean summer temperature is much higher in Turin, Alexandria, Pavia, and Guastalla, than in the seaside towns of Naples and Leghorn. The heat during the months of July and August is by no means greater at Rome and Florence than at Turin, Aosta, Moneliere, and Milan. In the northern provinces, the mean temperature of the month of April is a little higher than that of the whole year, while the mean temperature of October is a trifle lower. In the central and southern provinces, the reverse takes place, October being much hotter than April. (British Medical fournal, 1878.) 